\title{
Integralidade como norteadora da formação interprofissional: relato de experiência da reformulação curricular dos cursos da Escola de Saúde UNISINOS
}

\author{
Ana Paula Barcellos Karolczak, Ana Rita Breier, Isa Mara da Rosa Alves, Priscila Provin, Juliana
} Fátima da Silva Chaves, Paula Dal Bó Campagnolo

\section{Resumo}

Introdução: A Educação Interprofissional (EIP) tem-se apresentado como a principal estratégia na graduação em saúde para formar profissionais preparados para o trabalho em equipe e voltados para o cuidado integral (BATISTA, 2012). Objetivo: Relatar a experiência de construção de um projeto para implantação de atividades interprofissionais na Escola de Saúde da Universidade do Rio dos sinos (UNISINOS), uma universidade privada, localizada em São Leopoldo/RS. Método: (1) Foi realizado um levantamento inicial das Atividades Acadêmicas (disciplinas) da Escola de Saúde; (2) revisão e atualização das caracterizações das Atividades Acadêmicas (as caracterizações das AA contemplam a descrição das competências e conhecimentos que devem ser desenvolvidos). Para realizar o levantamento inicial as AA foram agrupadas por áreas de conhecimento específico, juntamente com a descrição das competências e dos conhecimentos previstos nas caracterizações. A partir dessa descrição, foi possível realizar uma análise qualitativa, relacionando as Atividades Acadêmicas com suas competências e/ou seus conhecimentos com potencial para atividades interprofissionais. Foi realizada uma escuta dos Coordenadores, professores e grupos de alunos para construção de uma identidade de formação acadêmica dos cursos que compõem a Escola de Saúde. Após esse movimento, foi possível realizar um mapeamento das necessidades de ajustes nas caracterizações. Objetivando consolidar a implantação de atividades interprofissionais foi apresentada uma proposta de nova organização das Atividades Acadêmicas. Fizeram parte desta análise todas as atividades acadêmicas dos seguintes cursos: Biomedicina, Ciências Biológicas (Licenciatura e Bacharelado), Educação Física (Licenciatura e Bacharelado), Enfermagem, Engenharia Biomédica, Farmácia, Fisioterapia, Nutrição, Serviço Social e Gestão Hospitalar. Resultados: Esse estudo evidenciou a recorrência de competências presentes em Atividades Acadêmicas da mesma área de conhecimento, apenas com nomenclaturas e codificações diferentes em cada curso. Além disso, percebeu-se uma fragmentação do conhecimento, não proporcionando ao aluno a vivência de experiências com professores e colegas de áreas correlatas, dificultando a formação para atuação em equipes multiprofissionais. Vale mencionar, ainda, uma questão operacional importante ao tratar-se de uma universidade privada: a oferta de AA específicas para cada curso dificulta a flexibilização de horários de turmas para os alunos e, muitas vezes, acarreta baixa densidade de ocupação das salas de aula, elevando custos e dificultando a efetivação de maior número de turmas. Considerando esses elementos, e após um profundo estudo sobre os currículos dos cursos de Graduação da Escola de Saúde UNISINOS, foi construído um projeto que contribuirá para um alinhamento na formação profissional dos cursos da Escola e norteará futuras revisões curriculares dos cursos de graduação da Escola da Saúde, de modo que não mais sejam replicadas competências. A proposta desta formação contempla o conceito de um ser humano integral (biopsicossocial e espiritual vivendo em um contexto social), estudado a partir de duas Unidades Temáticas (Biológica e Social). Essas temáticas desenvolvem-se no cenário do sistema de saúde brasileiro destacando-se a "humanização" como potencializadora das relações interprofissionais e de cuidado à saúde das pessoas. Todas essas competências propostas deverão ser desenvolvidas tendo como base a "Saúde Coletiva" como norteadora do "Trabalho em Saúde" - seja no cuidado do usuário/paciente, seja no trabalho em equipe - e da "Pesquisa em Saúde" - como precursora do 
ISSN 2179-6750

planejamento e do monitoramento das ações em saúde e como produtora de conhecimento em saúde. As Unidades temáticas são comuns aos cursos da Escola de Saúde e interagem entre si de forma transversal. Cada Unidade Temática Transversal comum é composta de um núcleo comum de Atividades Acadêmicas dos cursos da Escola de Saúde, bem como de um núcleo de aprofundamento que contempla necessidades específicas dos cursos. Com objetivo de viabilizar a implantação das Unidades temáticas, elaborou-se uma sugestão de itinerário curricular para as Atividades Acadêmicas, contemplando a semestralização e a indicação de pré-requisitos. Trata-se de uma sugestão que visa contribuir para o alinhamento da oferta sem prejuízos a autonomia dos Planos Curriculares. Além disso, em um segundo plano, o compartilhamento de Atividades Acadêmicas contribui para a sustentabilidade institucional, que ocorre pela otimização de espaço físico e de recursos humanos. Conclusão: A Escola de Saúde da UNISINOS assumiu a educação interprofissional como norteadora da formação em saúde, o que implica aspectos positivos para a formação acadêmica a partir do momento que essa estratégia busca desenvolver maior conscientização e preparo para a prática, fomentar a socialização entre profissionais da saúde, desenvolver a capacidade de trabalho em equipe, a liderança, e o protagonismo, desenvolver a habilidade de tomada de decisões, e desenvolver competências comuns e específicas (CÂMARA, 2014). A partir disso, a organização curricular proposta deixa de ser estruturada a partir de Eixos Transversais e passa a adotar uma organização por Unidades Temáticas Transversais desdobradas em áreas de conhecimento que se materializam em AAs. Trata-se de uma alteração que considera áreas fundamentais de formação em saúde, que passarão a fazer parte do currículo de todos os cursos da área na UNISINOS, potencializando oportunidades de vivências interprofissionais como estratégia pedagógica para qualificar a formação em saúde.

Descritores: Educação, Integralidade em saúde, Equipe interdisciplinar em saúde, Profissionais de saúde, Relações interprofissionais 